\title{
A Review on Ethical Issues and Rules in Psychological Assessment
}

\author{
Reyhan Arslan ${ }^{1}$
}

\begin{abstract}
Psychologists that offer psychological counseling may use psychological tests and some other measurement techniques in psychological assessment. On the other hand, they may encounter with many ethical dilemmas while doing these assessments. In this review, firstly the definition, purposes, and the stages of psychological assessment are explained. After that, ethical rules of psychological assessment are examined in ways that include both tests and other techniques in the context of ethical principles in the Ethical Guidelines of American Psychological Association. Besides, these ethical rules are discussed in the light of findings in the related literature. In the final part, other ethical issues which are psychologist-counselor relationship in psychological assessment, computer-based assessment, psychological assessment in rural and low-income areas, and assessment of mentally retarded people are mentioned and some suggestions that can be considered in doing an ethical assessment are presented.
\end{abstract}

Keywords: psychological assessment, ethics, APA

\section{INTRODUCTION}

Psychological assessment involves the evaluation process of individuals' skills, behaviors and personal attributes using various psychological methods such as interview, observation and other assessment tools (Welfel, 2013). It makes a major contribution to the decision making process for determining the most appropriate research method to be implemented (Hood and Johnson, 2008). Additionally, when performed at certain intervals during an ongoing treatment process, psychological assessment helps to understand whether the implemented treatment is effective (Groth-Marnat, 2009). Consequently, psychological assessment aims to provide information as to the individual's cognitive skills, behaviors and abilities; experienced psychological issues, constraints and the underlying factors; and the individual's functionality and therapeutic requirements. In this context, psychological assessment holds critical importance as it may change the course of an individual's life through determining the direction of his/her treatment (Meyer et al., 2001). Psychological assessment does not only underline an individual's weaknesses, but also lays emphasis on his/her strengths. In this way, it helps individuals to use their existing capabilities in a more efficient way through rehabilitating their weaknesses or selecting a program that helps to enhance their strengths (Koocher and Keith-Spiegel, 1998). Psychological assessment does not rely merely on test scores; since each individual features diverse skills that can be evaluated through various methods. Accordingly, a psychologist is not the person who merely performs and grades psychological tests (Groth-Marnat, 2009), although such tests are widely regarded as beneficial tools for the assessment process (Hambleton, Merenda and Spielberger, 2005). Assessment of the individuals' mental, emotional, social, linguistic and psycho-motor development and providing an account of their personalities, behaviors and skills constitute the intended use of

1 Research Assistant, Istanbul Medipol University, Faculty of Educational Sciences, reyhanarslan@medipol.edu.tr 
psychological tests which are indispensable tools for psychologists in a psychological assessment process (Koocher and Keith-Spiegel, 1998). Psychological tests can be also useful in diagnosis; however, diagnosing on the sole basis of test results should be strictly avoided (Szasz, 1970). Certainly, no psychological assessment method alone could suffice to evaluate a specific attribute, skill or tendency of an individual and it would not be possible to obtain an accurate result regarding that subject (GrothMarnat, 2009). Consequently, psychological assessment methods involve all processes of measurement and evaluation stages in which various tests, clinical observations and interviews are used to determine the tendencies of individuals in specific subjects, their skills, personal attributes and psychological problems. The therapy process is specified with an integrative approach through gathering the information obtained via interviews with the client and/or his/her family, observations and test results. As a result of these efforts, the course of treatment is determined by the joint decision of client and the psychologist (Welfel, 2013).

\section{Phases of Psychological Assessment}

Maloney and Ward (1976) specified a seven-phase model to define the psychological assessment process. However, these authors also stated that, these seven phases do not proceed with a strict linear interaction, and in most of the cases, they even overlap and occur concurrently. The phases of this model established to define the psychological assessment process are briefly described below.

First phase. The first phase involves gathering information as to the client. Firstly, the factors that prompt the client to search for treatment/aid are sought. At this point, the psychologist starts to establish a basis for his/her temporary hypotheses about the client while proceeding with asking questions to obtain more detailed information. Afterwards, the psychologist performs various psychological tests to understand the client's situation. The psychologist, meanwhile, constantly observes and takes note of the attitudes and behaviors of the client during the interview and the test. In this way, the psychologist makes use of the non-verbal data obtained with observation, in addition to the objective data such as verbal statements and test scores. In this phase, the hypotheses about the client are at a preliminary level and likely to change with addition of new information.

Second phase. In the second phase of psychological assessment, the focus is on diversification and elaboration of the inferences regarding the client. These inferences serve to a summarizing and descriptive function. For instance, when the psychologist makes an inference as to the possibility that the client is suffering from depression, this inference both summarizes the general status of the client and accounts for his/her retarded motions, focusing issues, undergoing flat effect etc. In the next step, psychologist attempts to determine whether the client's situation is chronic, or if it developed against a situational difficulty encountered by the client. In this period, psychologist draws on information obtained from test scores or other sources, if available. Consequently, the aim of this phase is to develop multiple inferences about the client to direct further inquiries.

Third phase. This phase involves acknowledgement or refusal of the inferences made in the second phase. An inference is completely true in rare situations; the validity of an inference increases as the psychologist evaluates the consistency and strength of the data that supports a given inference. For instance, an inference made on the grounds that the client is anxious can be supported with MMPI 
scores or behavioral observations. The abundance of evidences supporting an inference has a direct effect on the level of confidence in that specific inference.

Fourth phase. In the fourth phase of psychological assessment, the psychologist attempts to reach more general inferences developed for the client throughout the first three phases. In other words, in this phase, specific inferences are elaborated to gain insight into the general behavioral patterns of the client. Briefly, elaboration of the explanations related to the client's situation, and developing these explanations are aimed in this phase.

Fifth phase. This phase involves further elaboration of various personal characteristics of the client. This phase may also involve discussion and definition of general factors such as the client's cognitive functions, affection and mood, and the level of interpersonal functionality. Although they look like similar, as compared the fourth phase, the fifth phase provides a more inclusive and integrative definition about the client.

Sixth phase. In this phase, the comprehensive definition as to the client is placed in a situational frame. In a sense, the definitions regarding the client are evaluated in a situational context.

Seventh phase. In this last phase of assessment, specific predictions are made with reference to the client's behaviors. This phase is the most critical one in the decision making process and requires the psychologist to take account of the relationship between personal and situational variables.

\section{Ethical Guidelines Regarding Psychological Assessment}

Implementation of psychological assessment in an ethical frame holds critical importance in terms of reliability of the assessment results. In this context, the psychologist performing the assessment must be aware and well informed of the ethical rules and guidelines (Pope and Vasquez, 2010). Yet, in some cases psychologists working in the field may encounter contradictions - although ethical rules are explicitly stated - and undergo difficulties in making decisions within ethical frame; and accordingly they may seek support for that specific issue. In this context, this review study was conducted with a view to provide psychologists with an insight into the ethical rules and principles that should be followed during the psychological assessment process, and to make suggestions through calling attention to certain contradictions and gaps in the field. In this context ethical issues in psychological assessment were discussed within the frame of American Psychological Association's Ethics Code (2010) which is one of the most widely consulted institutions that establishes worldwide ethical principles and standards in the field of mental health.

Bases for assessment. "Psychologists base their assessments, suggestions, reports and opinions as to diagnoses upon findings, information and techniques that suffice to prove their results." (Standard 9.01a, Bases for Assessment [APA, 2010]). According to "Standard 9.01b, Bases for Assessment": "Psychologists provide an opinion only after they have supporting evidence of that opinion, obtained after sufficient research. If conducting such research is not possible, psychologists report their efforts and outcomes of their efforts. Psychologists examine the possible influence of their limited knowledge on the reliability and validity of their assessments and confine their findings or suggestions accordingly" (APA, 2010). 
Use of assessments. "Psychologists perform, score, interpret and use assessment techniques, interviews or tools in accordance with the diagnoses or research" (Standard 9.02a, Use of Assessments [APA, 2010]). As stated in Standard 9.02b, Use of Assessments principle, psychologists should use assessment tools, reliability and validity of which are verified on samples that are equivalent to the subject of their application. In case a test is used without verification of its validity and reliability, psychologist must explain the strengths and limitations of the results and their interpretations (APA, 2010). According to Berndt (1984), psychologists should determine as to whether the sample of the test is similar to the individual being tested, as a means for generalizability of the results. Rosen, Reaves and Hill (1989) stated that, when choosing among the tests for a client, psychologists should pay regard to the validity and reliability level of the test and its compliance with the norms. The use of tests with high validity and reliability reduces biases and judgment mistakes; and tests enable comparison of individuals with normative groups (Turchik, Karpenko, Hammers and McNamara, 2007). The most critical issue that should be regarded is that tests should never be used for inappropriate cases and individuals even though they have suitable psychometric properties (Standard 8.13, Inappropriate Use of Tests [Turkish Psychological Association, 2004]). This is mainly ascribed to the fact that, inappropriate use of a test, outside the scope of its intended use, is very likely to result in invalid or useless inferences, which is a really undesirable situation (Novick, 1981). Beside its validity and reliability, legal and ethical compliance of the psychological test should also be questioned (Kaplan and Saccuzzo, 2012). In standardized tests, test application environments and processes are basically assumed to be identical for each person (Haney, 1981). If psychologists fail to pay enough attention to applying identical processes in compliance with the norms, standardized norms lose their applicability and test results come into question (Groth-Marnat, 2009; Hood and Johnson, 2008). Therefore, in so far as they can do, psychologists should implement the tests under the conditions in which they are standardized. Otherwise this should be explicitly stated and reliability of the results should be questioned (Matarazzo, 1990). If the use of an alternative language is outside the scope of the assessment, psychologist should use assessment methods in accordance with the individual's preference for language and his/her capability to use that specific language (Standard 9.02c, Use of Assessment [APA, 2010]). Accordingly, psychologist should determine the language used by client and client's proficiency in that language. Groth-Marnat (2009) suggests that, conducted assessments and used assessment tools should be - so far as possible - in native language of clients.

Informed consent. Informed consent is a crucial step in establishment of the confidential relationship between a psychologist and a client (Fisher, 2016). Clients can decide as to whether they will participate in psychological assessments based on the information they receive through an informed consent (Barnett and Brad Johnson, 2008). After providing the client with information regarding the psychological assessment's aim, procedure, period, alternatives, details regarding the appointment, the nature and limitations of confidentiality, price and assessment, his/her written or verbal consent is received (Knapp and VandeCreek, 2006). Consequently, psychological assessment process begins only after it is ensured that the individual is well informed about the nature, aim and technique of the psychological assessment and his/her consent is received (Pope and Vaquez, 2010). According to APA (2010) Ethics Code Standard 9.03a, Written Consent in Assessment: "Psychologists must take clients' consent for assessment and diagnosis related services" with exception of the following situations: 
1) If the test is requested through laws or legislative regulations

2) If the test is implemented as a routine activity of an institution or a training unit (participants may have volunteered for assessment during a job application, etc.)

3) If the test is applied to assess the decision making capacity of individual

Another important issue about taking informed consent is receiving the consent of individuals with limited or impaired consent capacity. As stated in Standard 9.03b, Informed Consent in Assessment principle, individuals with questionable capacity, or the ones subject to legal institutions' permission for assessment, should be informed as to the objective and procedure of the assessment with a plain and simple language, prior to receiving their consents (APA, 2010). The psychological assessment of elder people with impaired cognitive processes also requires psychologists to inform clients with a plain language and receive their consent accordingly (McGuire, 2009). If psychologist will use a translation service, he/she must also receive the consent of client to use such service (Standard 9.03c, Informed Consent in Assessment [APA, 2010]).

Release of Test Results. As the optional or obligatory release of test data is regulated by complex legal and ethical standards, psychologists often encounter ethical contradictions in this subject (Pope and Vasquez, 2010). Tranel (1994) stated that particularly in legal situations psychologists are often asked for the raw test scores and this places them in an ethical dilemma between judicial requests and ethical rules as it is strictly disapproved by ethical rules to submit raw test scores to unqualified individuals. APA Ethics Code (2010) addresses the definition and release of test results as follows (Standard 9.04, Release of Test Data):

(a) "Test data, raw and scaled scores involve the responses of clients to test questions or other stimuli, as well as the notes and records taken by psychologists in relation to the dialogues or behaviors of clients. Answers of clients to test questions are also covered by the definition of 'test data'. Psychologists can submit test data to clients or their assignees only upon the client's consent. As a means for protection of the client or third persons from possible harm or prevention of misuse or misinterpretation of the test, psychologist may avoid releasing test data".

(b) "In cases where no representative of the client is present, psychologists must release test data only under legal conditions and if demanded by courts".

Additionally, according to Turkish Psychological Association Ethics Code (2004), if assessments results are to be shared within the frame of training purposes, personal information of the assessed individual should not be released (Standard 8.12, Release of Training-Related Assessments).

Test construction. Aside from using the existing tests, psychologists can also construct new testing tools. However some points should be considered while constructing tests. These points are addressed in American Psychological Association's Ethics Code (2010) as follows:

"Psychologists constructing a psychological test or another assessment tool must implement proper psychometric processes and use up-to-date scientific information in terms of standardization, reliability, validity of the test and mitigation or elimination of biases" (Standard 9.05, Test Construction). 
Compliance to the cultural norms holds critical importance during the construction of test (Hambleton et al., 2005). Otherwise, the performed test may yield inconsistent results, which in turn may invalidate the test results. In other words, interpretation of the results of tests, developed without compliance to cultural norms, is likely to yield misleading inferences about the individuals who are subject to testing (Gottfredson, 1994). All these mentioned criteria should be regarded and implemented for adapted tests, as well (Brown, 1994).

Interpreting assessment results. "While interpreting assessment results, psychologists pay regard to various factors likely to impair the validity of their interpretations or influence their inferences, individual's testing skills, and other attributes of the assessed person (language, cultural differences, etc.), and the aim of the assessment. If psychologists are of the opinion that their interpretations are significantly limited, they mention this issue while reporting." (Standard 9.06, Interpreting Assessment Results" [APA, 2010]. In this context, while interpreting assessment results, psychologists should take into account the effect of socio-economic, ethical and cultural factors (Suzuki and Ponterotto, 2008). While stating their opinions regarding the test results, psychologists should also be well aware that, the assessed individual's cultural and social attributes and language are likely effective on the test results and they should explicitly state the extent to which the conducted assessment could be influenced depending on these attributes (Hambleton et al, 2005; Suzuki and Ponterotto, 2008). Psychologists must always pay particular attention while assessing individuals that are not represented in the norm group of the standardized test, and they must comply with testing boundaries. If nevertheless psychologists are obliged to apply the test, they should consider the limitations in interpretation of the test results and mention these in their report (Hood and Johnson, 2008). In case of an external factor, which is assumed to have influence on the results of the implemented test (e.g. noisy environment) or if the individual is under the effect of drug or other substances during assessment, or if there is a questionable situation as to whether the individual has shared all attributes regarding the reference group that provides basis for norms, these factors should also be taken into account during interpretation and explicitly stated in the report (Pope and Vasquez, 2010).

Assessment by unqualified persons. Application, scoring and interpretation of different tests necessitate different competency levels (Campbell, Vasquez, Behnke and Kinscherff, 2010). Psychologists are required to have received proper training to perform and interpret psychological tests, which generally involves post-graduate education and supervision (Turner, DeMers, Fox and Reed, 2001). Psychologists are also supposed to equip with specific skills related with psychological assessment. Such skills involve the evaluation of strengths and shortcomings of a test, selection of suitable tests, having an insight into the issues about the test's reliability and validity, and interpretation of diverse results received from various populations (Fisher, 2016; Turner et al., 2001). In this context, the person performing the test should be aware of his/her competency boundaries and should not undertake the works that exceed his/her capabilities (Barnett and Brad Johnson, 2008; Kaplan and Saccuzzo, 2012). People, especially the ones using computer-based interpretations, should be trained in this field (Murphy and Davidshofer, 2005). According to APA Ethics Code (2010), "Psychologists do not give permission for the use of psychological assessment techniques by unqualified people with exception of educational works performed under supervision" (Standard 9.07, Assessment by Unqualified Persons). 
Obsolete tests and outdated test results. Psychologists should not base their assessments, decisions or suggestions about a treatment on obsolete, invalidated and outdated information or test results (Standard 9.08, Obsolete Tests and Outdated Test Results [APA, 2010]). Psychologists should implement up-to-date tests and methods in their assessments (Murphy and Davidshofer, 2005). Psychologists must also avoid making interpretations based on the tests previously performed on individual as they may have become invalidated. Interpretations should be made on the basis of up-to-date test data (London and Bray, 1980).

Test scoring and interpretation services. According to APA (2010) Ethics Code (Standard 9.09, Test Scoring and Interpretation Services) and Turkish Psychological Association (2004) Ethics Code (Standard 8.9, Test Scoring and Interpretation Services), psychologists must properly define the goals, norms, validity, reliability and application conditions of their works while providing their colleagues with assessment or scoring services. It is also stated in both ethics codes that, regardless of whether they make the scoring or interpretation themselves; or whether they make use of software, psychologists should undertake the responsibility to ensure the proper use of application, interpretation and assessment tools.

Explaining assessment results. As long as it does not forbidden by laws or ethical principles or the client is not negatively affected, psychologist mustn't withhold the test results from client (Bernet and Dulcan, 1999). "Psychologists are required to convey the test results to clients subject of assessment or one of their representatives completely with a clear and plain language" (Standard 9.10, Explaining Assessment Results [APA, 2010]). If presentation of assessment results to the assessed individual is not deemed proper (corporate consultancy, recruitments, forensic assessment, etc.), client should be notified of this situation before the assessment process starts (Standard 8.10, Explaining Assessment Results [Turkish Psychological Association, 2004]).

Maintaining test security. "Test equipment involves test materials, guidelines, various tools, protocols and test questions. Psychologists are responsible for maintaining the integrity and security of tests and other assessment techniques in compliance with laws and contractual liabilities and this Ethics Code herein, also in consideration of copyrights." (Standard 9.11, Maintaining Test Security [APA, 2010]). Release of test materials to unqualified/untrained people is a violation against copyrights (Tranel, 1994). Additionally, when a developed test is to be translated or adapted or such test is to be utilized, consent of the original test's developer or publisher must be received. Partial modifications or reprinting of published tests should be prevented and copyrights must be respected (Koocher and Keith-Spiegel, 1998; Oles and Davis, 1977).

\section{Other Ethical Issues in Psychological Assessment}

Psychologist-client relationship in psychological assessment. The quality of the relationship between psychologists and clients holds great importance in psychological assessment (Ackerman, Hilsenroth, Baity, and Blagys, 2000). Therefore, psychologists should be aware of their influence on clients and endeavor to bring the quality of this relationship to the highest possible level. Feldman and Sullivan (1971) reported that, when a good psychological-client relationship was established with elder children - verbal appraisal and a sincere speech - children were found to receive higher WISC-R scores (13 points higher) compared to the other group in which the test was performed with a more neutral speech (as 
cited in Groth-Marnat, 2009). According to another study, when compared with neutral or approving comments, disapproving comments of psychologists such as: "I thought you could do better than this" were found to result in a significant decrease in test performance (Witmer, Bornstein, and Dunham, 1971). However, to ensure standardization, feedbacks and the level of the established relationship should be kept at a certain level as far as possible in all tests (Groth-Marnat, 2009). In conclusion, a wellestablished relationship and feedback between psychologists and clients may significantly improve individuals' test performance. In this context, one of the priorities of psychologists in psychological assessment should be establishing a good relationship with their clients (Finn, 2007).

Assessment in rural and low-income regions. Psychologists in regions with low socioeconomic levels can be more likely to violate ethical rules. For instance, people living in these areas may be more concerned about confidentiality (Hargrove, 1986). As for the case of psychological assessment in rural areas with lower socioeconomic levels, clients may be uninsured; they may not be able to afford services; hospitals may have limited means and sources, thus being unable to afford assessment tools (Suzuki and Ponterotto, 2008). Most of the hospitals may still be using obsolete/disused tests. Geographic isolation, on the other hand, is another cause for concern (Barry, Doherty, Hope, Sixsmith and Kelleher, 2000). It was stated in a review study of Turchik et al. (2007) that, psychologists working in such regions encounter more difficulties in consulting with their colleagues about complex assessments as compared to psychologists working in large cities. Psychologists working in rural areas can also have trouble in referring their clients to another competent colleague of theirs about a subject that they feel inadequate, since such professionals are likely to be resident in far places (Turchik et al., 2007). In another review study, competency related ethical dilemmas about assessments faced by psychologists living in rural areas, were addressed. One of these dilemmas is that psychologists living in these areas may from time to time be obligated to conduct the tests that they are not trained for, due to the insufficient number of qualified professionals. In such situations, psychologists can apply such tests under the supervision of a qualified colleague of theirs (Werth, Hastings, and Riding-Malon, 2010).

Assessment of children. Children may undergo psychological assessments for several reasons: through guidance by school counseling, parents' concern about the changes in child's condition, or routine controls (Hood and Johnson, 2008). In general, all ethical rules mentioned in this study also apply to the assessment of children. In the case of children's psychological assessment, however, particular attention should be paid to the issue of receiving informed consent. Adults are deemed authorized to give informed consent unless they are proved to legally incapacitated. However, children under the age of 18 are not deemed authorized to give an informed consent. Therefore, informed consent should be received from the child's parents (Pope and Vasquez, 2010).

Assessment of mentally disabled individuals. Even though patients have limited consent capacity as a result of their mental disability, psychologists should convey the nature and goal of the assessment to patients with a simple language and receive their consent accordingly. Patients can be informed as to the possible consequences of their consent for psychological assessment through use of simple expressions, open-ended questions and illustrative examples (Bernet and Dulcan, 1999). In some cases, minor modifications on standard application procedures of assessment tools are recommended as a means for yielding more valid results during the assessment of mentally disabled individuals. However, implementers of the tests should be previously notified of such modifications and these modifications 
and they should mention them in their reports (Lee, Reynolds and Wilson, 2003). Some of the tests other than intelligence tests are also sensitive to the attributes of individuals such as their cognitive functions, linguistic skills, etc. Therefore, psychologists should be notified of the modifications on these tests as well, and they should carry out the test procedure accordingly (Whitehouse, Tudway, Look and Kroese, 2006). In case interpretation of test findings are called into question due to the mental disability of a patient, this situation should be regarded as a limitation while conveying the test results and the situation should be stated accordingly (Adams and Boyd, 2010). Even though few mentally disabled people apply for a psychological assessment on their own, submission of test results and related suggestions generally turns out to be helpful, and this may help individuals in developing healthy coping strategies. While providing mentally disabled individuals with feedback as to their assessment results, psychologists should consider their cognitive and verbal skills and ensure that feedbacks are conveyed in a comprehensible form (Adams and Boyd, 2010).

Computer-assisted psychological assessment. Computer assisted psychological assessment have been increasingly applied in the last 30 years. The percentage of psychologists that reported to apply computer assisted psychological assessment increased from 17\% to 40\% between the years 1990-1999 (McMinn, Buchanan, Ellens and Ryan, 1999). The use of computer-assisted assessment brings several advantages, such as saving time and money, reduced implementer biases and increased test-retest reliability (Butcher, Perry and Hahn, 2004). In the past, the use of computer-assisted assessments was in a questionable position especially in terms of reliability and validity, whereas it has become a widely favored and reliable application in recent years (Groth-Marnat, 2009). According to related studies, the reliability and validity of computer assisted assessments were reported be as high as those performed in written form (Butcher, Perry and Atlis, 2000; Butcher et al., 2004). All previously mentioned ethical rules also apply to computer assisted assessments and implementers are supposed to comply with these rules (Murphy and Davidshofer, 2005). Psychologists, implementing the tests, should be trained qualified in interpretation of test results; also psychologists should avoid implementing tests that are out of their competency (Fisher, 2016). Additionally, psychologists should undertake the responsibility to ensure that application and scoring programs yield accurate results and the outputs are interpreted correctly (Turner et al., 2001).

\section{CONCLUSION}

With its numerous aspects such as interviews, observations and psychological tests, psychological assessment provides critical information as to individuals' cognitive competencies, behaviors, personality, emotions and thoughts and psychological problems with underlying factors and their effects on individuals' daily lives. Although psychological assessment does not merely involve implementation of psychological tests, the use of psychological tests holds great importance in this process. Psychological assessment process involves specific phases. Rather than being separated by strict lines, overlapping of these phases according to the context is crucial in terms of integrity of the assessment process. The effect of psychologist-client relationship's nature and feedbacks on assessment results has been revealed by several studies. In this context, the primary aim in the psychological assessment process should be providing a well-established relationship with the patient (Finn, 2007). 
Numerous studies in the literature provide guidance to the researchers studying in this field regarding the ethical issues and ethical rules that should be followed. Compliance to ethical rules during psychological assessments firstly entails the internalization of ethical principles. Psychologists that are aware of ethical principles and rules can more easily solve ethical dilemmas encountered during the course of psychological assessment process (Pope and Vasquez, 2010). The following suggestions are presented with a view to provide psychologists with guidance as to the application of psychological assessment within the boundary of ethical rules:

1) Psychologists should base their assessments, impressions and suggestions upon sufficient findings, information and techniques that prove their results.

2) When choosing among a number of tests for clients, psychologists should pay regard to the validity and reliability level of the test and its compliance with the norms. Psychologists should implement the tests under the conditions they are standardized.

3) Written or verbal consent should be taken only after it is ensured that the client has a complete understanding of the nature, aim and technique of the assessment process. However consent should be received from the parents for assessment of individuals under the age of 18.

4) During interpretation of assessment results, psychologists should take into account the effect of socioeconomic, ethical and cultural factors; and they should explicitly state the extent to which the conducted assessment could be influenced by these attributes.

5) Implementation, scoring and interpretation of different tests require different competency levels. Psychologists should be qualified and competent in their field and they should have received proper training for implementation and interpretation of the test to be performed. Implementers of computed assisted assessment methods should also be trained regarding the implementation and interpretation of these methods.

6) Psychologists should apply up-to-date tests and methods in their assessments and avoid basing their inferences regarding their client to obsolete and disused information or test results.

7) Psychologists should convey the test results to clients or one of their representatives completely with a clear and plain language.

8) Psychologists working in rural areas encounter more ethical contradictions as compared to psychologists working in large cities. Psychologists living in these areas may be obligated to conduct the tests that they are not trained for; in such situations, tests can be applied under the supervision of a qualified psychologist.

9) During psychological assessment of mentally disabled individuals, psychologists can make minor modifications on standard application procedures of assessment tools to obtain more valid results. Implementers of the test should be previously notified of this situation and they should mention such situations in their reports.

10) Psychologists applying the tests should pay particular attention to establishing a good relationship with the client. 


\section{REFERENCES}

Ackerman, S. J., Hilsenroth, M. J., Baity, M. R., \& Blagys, M. D. (2000). Interaction of therapeutic process and alliance during psychological assessment. Journal of Personality Assessment, 75(1), 82-109.

Adams, Z. W., \& Boyd, S. E. (2010). Ethical challenges in the treatment of individuals with intellectual disabilities. Ethics E Behavior, 20(6), 407-418.

American Psychological Association. (2010). Ethical principles of psychologists and code of conduct. http://www.apa.org/ethics/code/index.aspx adresinden alınmıştır.

Barnett, J. E., \& Brad Johnson, W. (2008). Ethics desk reference for psychologists. Washington, DC: American Psychological Association.

Barry, M. M., Doherty, A., Hope, A., Sixsmith, J., \& Kelleher, C. C. (2000). A community needs assessment for rural mental health promotion. Health Education Research, 15, 293-304.

Berndt, D. J. (1984). Ethical and professional considerations in psychological assessment. Professional Psychology: Research and Practice, 14, 580-587.

Bernet, W., \& Dulcan, M. (1999). Practice parameters for the assessment and the treatment of children, adolescents, and adults with mental retardation and comorbid mental disorders. Journal of the American Academy of Child and Adolescent Psychiatry, 38, 5-31.

Butcher, J. N., Perry, J. N., \& Atlis, M. M. (2000). Validity and utility of computer-based test interpretation. Psychological Assessment, 12(1), 6-18.

Butcher, J. N., Perry, J., \& Hahn, J. (2004). Computers in clinical assessment: Historical developments, present status, and future challenges. Journal of Clinical Psychology, 60, 331-345.

Campbell, L., Vasquez, M., Behnke, S., \& Kinscherff, R. (2010). APA Ethics Code commentary and case illustrations. Washington, DC: American Psychological Association.

Finn, S. E. (2007). In our clients' shoes: Theory and techniques of therapeutic assessment. Mahwah, NJ: Lawrence Erlbaum Associates.

Fisher, C. B. (2016). Decoding the ethics code: A practical guide for psychologists. California: SAGE Publications.

Gottfredson, L. S. (1994). The science and politics of race-norming. American Psychologist, 49 (11), $955-$ 963.

Groth-Marnat, G. (2009). Handbook of psychological assessment. New Jersey: John Wiley \& Sons.

Hambleton, R. K., Merenda, P.F., \& Spielberger, C. D. (2005). Adapting educational and psychological tests for cross-cultural assessment. New Jersey: Lawrence Erlbaum Associates.

Haney, W. (1981). Validity, vaudeville, and values: A short history of social concerns over standardized testing. American Psychologist, 36, 1021-1034. 
Hargrove, D. S. (1986). Ethical issues in rural mental health practice. Professional Psychology: Research and Practice, 17(1), 20-23.

Hood, A. B., \& Johnson, R. W. (2008). Assessment in counseling: A guide to the use of psychological assessment procedures. USA: American Counseling Association.

Kaplan, R. M., \& Saccuzzo, D. P. (2012). Psychological testing: Principles, applications, and issues. USA: Wadsworth Publishing.

Knapp, S. J., \& VandeCreek, L. D. (2006). Practical ethics for psychologists: A positive approach. Washington, DC: American Psychological Association.

Koocher, G. P., \& Keith-Spiegel, P. (1998). Ethics in psychology: Professional standards and cases. New York: Oxford University Press.

Lee, D., Reynolds, C. R., \& Wilson, V.L. (2003). Standardized test administration: Why bother? Journal of Forensic Neuropsychology, 3(3), 55-81.

London, M., \& Bray, D. W. (1980). Ethical issues in testing and evaluation for personnel decisions. American Psychologist, 35, 890-901.

Maloney, M. P., \& Ward, M.P. (1976). Psychological assessment: A conceptual approach. New York: Oxford University Press.

Matarazzo, J. D. (1990). Psychological assessment vs psychological testing: Validation from Binet to the school, clinic and courtroom. American Psychologist, 45, 999-1017.

McGuire, J. (2009). Ethical considerations when working with older adults. Ethics E Behavior, 19(2), 112128.

McMinn, M. R., Buchanan, T., Ellens, B. M., \& Ryan, M. K. (1999). Technology, professional practice and ethics: Survey findings and implications. Professional Psychology: Research and Practice, 30, 165172.

Meyer, G. J., Finn, S. E., Eyde, L. D., Kay, G. G., Moreland, K. L., Dies, R. R., Eisman, E. J., Kubiszyn, T. W., \& Reed, G. M. (2001). Psychological testing and psychological assessment: a review of evidence and issues. American Psychologist, 56(2), 128-165.

Murphy, K. R., \& Davidshofer, C. O. (2005). Psychological testing: Principles and applications. New Jersey: Pearson.

Novick, M. R. (1981). Federal guidelines and professional standards. American Psychologist, 36, 10351046.

Oles, H. J., \& Davis, G. D. (1977). Publishers violate APA standards on test distribution. Psychological Reports, 41, 713-714.

Pope, K. S., \& Vasquez, M. J. T. (2010). Ethics in psychotherapy and counseling. A practical guide. New Jersey: John Wiley \& Sons. 
Rosen, G. A., Reaves, R. P., \& Hill, D. S. (1989). Reliability and validity of psychology licensing examinations: Multiple roles and redundant systems in development and screening. Professional Psychology: Research and Practice, 20, 272-274.

Suzuki, L. A., \& Ponterotto, J. G. (2008). Handbook of multicultural assessment: Clinical, psychological, and educational applications. San Francisco: Jossey-Bass.

Szasz, T. S. (1970). The manufacture of madness. New York: Harper \& Row.

Tranel, D. (1994). The release of psychological data to nonexperts: Ethical and legal considerations. Professional Psychology: Research and Practice, 25, 33-38.

Turchik, J. A., Karpenko, V., Hammers, D., \& McNamara, J. R. (2007). Practical and ethical assessment issues in rural, impoverished, and managed care settings. Professional Psychology, 38, 158-168.

Turner, S. M., DeMers, S. T., Fox, H. R., \& Reed, G. M. (2001). APA's guidelines for test user qualifications: An executive summary. American Psychologist, 56, 1099-1113.

Türk Psikologlar Derneği (2004). Türk Psikologlar Derneği Etik Yönetmeliği. http://www.psikolog.org.tr/upload/content/files/file_3_7.pdf adresinden alınmıştır.

Welfel, E. R. (2013). Ethics in counseling $\mathcal{E}$ psychotherapy: Standards, research, and emerging issues. USA: Brooks/Cole.

Werth, J. L., Hastings, S. L., \& Riding-Malon, R. (2010). Ethical challenges of practicing in rural areas. Journal of Clinical Psychology, 66, 537-548.

Whitehouse, R. M., Tudway, J. A., Look, R., \& Kroese, B. S. (2006). Adapting individual psychotherapy for adults with intellectual disabilities: A comparative review of the cognitive-behaviour and psychodynamic literature. Journal of Applied Research in Intellectual Disabilities, 19, 55-65.

Witmer, J., Bornstein, A., \& Dunham. R. (1971). The effects of verbal approval and disaproval upon the performance of third and fourth grade children on four subtests of the Wechsler Intelligence Scale for Children. Journal of School Psychology, 3, 347-356. 